\title{
Improved SHEPWM Strategy By The Robustness Optimization Algorithm In Multilevel Inverters With Equal DC Sources
}

\author{
Mahdi Vadizadeh ${ }^{1}$, Hadi Vadizadeh ${ }^{1}$ and Siamac Masoudi ${ }^{1}$ \\ I'Department of Electrical Engineering, Abhar Branch, Islamic Azad University, Abhar, Iran)
}

\begin{abstract}
A multilevel Inverters have many advantages such as reduced Harmonics, no need for a transformer, cost and loss reduction. In this paper the multilevel inverter with equal DC sources is used for THD optimization. Different modulation methods have been proposed to control the multilevel inverters. This paper focuses on the Selective Harmonic Elimination Pulse Width Modulation (SHEPWM) technique in multilevel inverter with equal DC sources. In the SHEPWM technique for multilevel inverters, in order to eliminate $N-1$ non-triplen odd harmonics of the $A C$-side voltage and to regulate the output line voltage amplitude, $N$ switching angles need to be determined. Therefore a set of $N$ non-linear transcendental equations must be solved to find the desired switching angles for any value of the modulation index. In this paper a new robustness optimization algorithm is presented to elimination of selective low order harmonics (LOH) in the output line voltage of the multilevel inverter based on the Multi Population Particle Swarm Optimization (MPPSO) algorithm. The switching angles are computed by a MPPSO algorithm to eliminate of LOH with high accuracy and determine the fundamental component to the desired value simultaneously. The proposed algorithm can generate stepped voltage waveforms with a wide range of modulation indices. The performance of the proposed algorithm for a seven-level cascaded H-bridge converter, based on simulation studies, is evaluated. MATLAB software is used for programming and simulation.
\end{abstract}

Keywords: Equal DC Sources, Multilevel Inverter, MPPSO Algorithm, Robustness Optimization Algorithm, Selective Harmonic Elimination PWM.

\section{Introduction}

Multilevel inverters have been acknowledged as possible prospects for medium and high power applications [1,2]. One of the most significant advantages of the multilevel inverters is the diminution of the harmonics in output waveforms without increasing the frequency, or decrease of output power of inverters. In many applications, it is desirable to get an $\mathrm{AC}$ output voltage with varying frequency and amplitude via inverters $[3,4]$. The variable speeds, AC motor drive system are one of the major areas of application for the variable frequency inverter $[5,6]$.

The most common topologies which are used in the prior article for multilevel inverter are included cascaded full bridge structure [7-9], the diode clamped structure [10] and flying capacitor structure [11]. The full-bridge structure needs fewer components to produce the same output waveform. In this paper, the full bridge structure is used, Because it's the most used topologies in industry, due to require a small number of components compared to other structures, also show lower harmonic distortion [12].

Various pulse width modulation (PWM) methods for multi-phase VSIs, have been developed for generating a sinusoidal output voltage [13]. To control the fundamental component and to eliminate the undesired harmonics of the output side voltages of a multilevel inverter, several pulse width modulation (PWM) methods, such as, selected harmonic elimination (SHE) [14], total harmonic distortion minimization [15], sinusoidal PWM [16] and space vector modulation techniques [17] have been suggested in previous literature. Among the surveyed PWM techniques, the SHEPWM is able to provide lower switching losses and to completely remove the low order harmonics from the AC side voltages $[18,19]$.

This paper focuses on the Selective Harmonic Elimination Pulse Width Modulation (SHEPWM) technique in multilevel inverter with equal DC sources. In the SHEPWM technique, in order to adjust the fundamental component and to eliminate N-1 non-triplen odd harmonics of the output side voltages of a multilevel inverter, $\mathrm{N}$ switching angles are required. Thus, $\mathrm{N}$ trigonometric equations specifying the harmonic content must be solved to find the answers for the switching angles. There have been many approaches to this problem reported in the technical literature including: sequential homotopy-based computation [20], resultants theory [21], optimization technique [22], Walsh functions [23] and Genetic Algorithms (GA) [24, 25].

The Newton-Raphson method has been used to solve transcendental equation in the literature [26] but this method has some drawbacks like divergence problems, require precise initial guess and gives no optimum solution [27]. Hence the heuristic algorithms such as common Particle Swarm Optimization (PSO) [28, 29] have the ability to combat the drawbacks like divergence problem. As an optimization technique, PSO is much less dependent on the start values of the variables in the optimization problem when compared with the widely used 
Newton-Raphson or mathematical programming techniques such as Sequential Quadratic Programming (SQP). Moreover, in this paper the new optimization algorithm called Multi Population Particle Swarm Optimization (MPPSO) is used to adjust fundamental component to the desired value and eliminate LOH with high accuracy in the wide range of modulation index. The MPPSO optimization algorithm has more advantages compared with a general optimization algorithm such as Genetic Algorithm (GA) or common PSO.

This paper includes the following parts. In the second section are offered Cascaded structure for multilevel inverter with equal DC sources. The third section is expressed MPPSO optimization algorithm along with SHEPWM nonlinear transcendental equations. Then in the fourth section are shown simulation results. Finally in the fifth Section will be presented conclusion of this paper.

\section{Cascaded Multilevel Inverter with Equal DC Sources}

There are three famous structure of multilevel inverter, Diode Clamped Multilevel Inverter (MI), Flying Capacitor MI and Cascaded Multilevel Inverter with Separate DC Sources (SDCSs). In this paper, is used of multilevel Cascaded Inverter with Separated DC Sources Structures [16]. A three phase M level structure of this inverter is shown in Fig. 1. The multilevel inverter using a cascaded inverter with SDCSs synthesizes a desired voltage from several independent sources of DC voltages, which may be obtained from either battery, fuel cells, or solar cells. So, an output voltage waveform can be generated by summation of the output voltage of each cell.

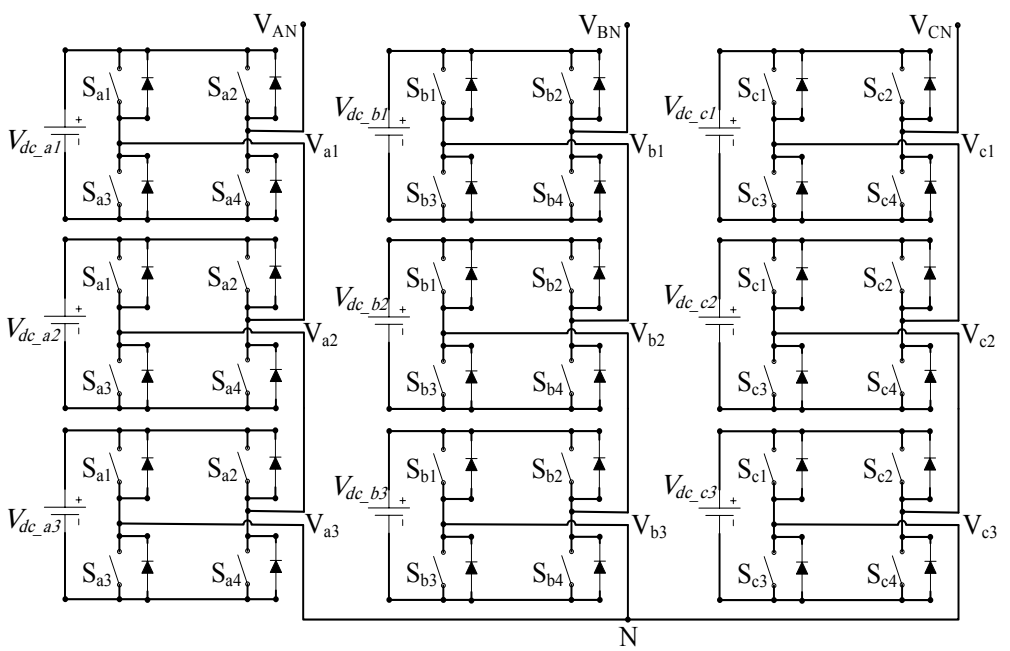

Fig. 1. Single-phase structure of a multilevel cascaded inverter.

Each SDCS is associated with a single-phase full-bridge inverter. This Structure has extreme advantages compared with another structure of inverters: least number of elements to produce the same waveform compares with another structure of inverters, eliminate of clamping diodes and etc. These advantages that have made it attractive in power conditioning systems and medium to high power drive applications [30]. The control in cascaded structure is simpler than another structure of inverter, unlike the Diode Clamped and Flying Capacitor inverters, each phase can be controlled separately and in addition, it also does not require the central controller, in other words the cascaded structures have only one independent controller on each phase.

Each separate DC source is linked with a single phase full-bridge inverter. The Different combination of 4 key $\mathrm{S}_{1}$ to $\mathrm{S}_{4}$ in each cell of the inverter can produce 3 different levels of voltage $\left(+V_{d c},-V_{d c}, 0\right)$. In this topology, the number of output phase voltage levels is defined by $\mathrm{m}=2 \mathrm{~S}+1$, where $\mathrm{S}$ is the number of $\mathrm{DC}$ sources. For example, a 7-level inverter has 3 SDCS. The quarter-wave symmetric waveform is used in this paper $[31,32]$. The voltage waveform which is shown in Fig. 2, has $\mathrm{S}$ switches angles in quarter-wave $\alpha_{1}, \alpha_{2}$, $\ldots, \alpha_{(s-1)}, \alpha_{s}$ and $4 S$ switching angles, $\alpha_{4 \mathrm{~s}}$, in each cycle. In this Paper, the DC voltages are assumed to be equal.

$$
V_{d c 1}=V_{d c 2}=\cdots=V_{d c(\mathrm{~S}-1)}=V_{d c S}
$$




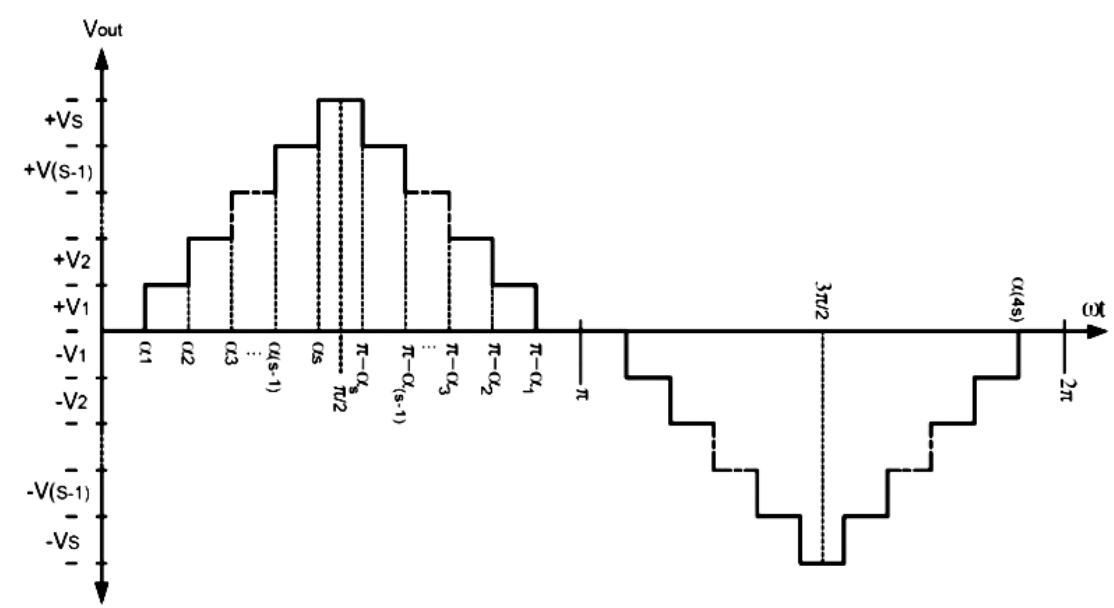

Fig. 2. The output waveform of phase voltage in multilevel inverter with an S number of SDCS as seriesconnected

Each cell is turned on and turned off in suitable angle. The first cell is turned on in $\alpha_{1}$ angle, the second cell is turned on in $\alpha_{2}$, etc. Then the first cell is turned off in $\pi-\alpha_{1}$ angle, the second cell is turned off in $\pi-\alpha_{2}$, etc. Finally is obtained output waveform with minimum THD. The Fourier series of multilevel waveform is as follows:

$$
V(\omega t)=\sum_{n=1}^{\infty} \mathrm{V}_{n} \operatorname{Sin}(n \omega t)
$$

$V_{a n}$ is the amplitude of the harmonic components of voltage, where are supposed DC sources as equal:

$$
V_{n}=\frac{4 V_{d c}}{n \pi} \sum_{i=1}^{S} \cos \left(n \alpha_{i}\right) \quad n=1,5,7,11,13, \cdots
$$

Where $S$ is the number of Full-Bridge cells. The switching angles $\alpha_{1}, \alpha_{2}, \ldots$, and $\alpha_{S}$ must satisfy the following constraint

$$
0<\alpha_{1}<\alpha_{2}<\cdots<\alpha_{S}<\frac{\pi}{2}
$$

\section{Implementation of MPPSO Algorithm to Solve SHEPWM Equations}

The intelligent method based on PSO algorithm is developed in this paper. The correction motion vector for each particle in PSO method is as follows:

$$
V_{i+1}^{k+1}=w_{i} v_{i}^{k}+c_{1} \text {.rand }\left(\text { pbest }-x_{i}^{k}\right)+c_{2} \text {.rand }\left(\text { gbest }-x_{i}^{k}\right)
$$

In Eq. (5), $V_{i}^{k}$ is the motion vector of $i^{\text {th }}$ particle in $k^{\text {th }}$ repetition. $V_{i}^{k+1}$ is a correction motion vector for $i^{\text {th }}$ particle. Rand is a random number in zero till one interval. $x_{i}^{k}$ is the current position of $i^{\text {th }}$ particle in $k^{\text {th }}$ repetition. pbest is the best answer of $i^{\text {th }}$ particle in all repetition, The index of the best particle among all the particles in the group is represented as gbest. $w_{i}$ is the weight coefficient for speed vector of $i^{\text {th }}$ particle and $C_{i}$ is the weight coefficient for each particle.

In this paper, use of more population in the main PSO algorithm, which can be determined arbitrary value for $N_{p}$ parameter, the $N_{p}$ is number of population. Also in $[33,34]$ to ensure convergence of the method is used by contraction coefficient $\mathrm{K}$, which their value is calculated according to the values of the weighting coefficients that is shown in Eq. (6).

$$
\begin{gathered}
V_{i+1}^{k+1}=K^{*}\left(w_{i} v_{i}^{k}+c_{1} \text {.rand } .\left(\text { pbest }-x_{i}^{k}\right)+c_{2} \cdot \operatorname{rand}\left(\text { gbest }-x_{i}^{k}\right)\right) \\
K=\frac{2}{\left|2-C-\sqrt{C^{2}-4 C}\right|} \quad \text { where } C=c_{1}+c_{2} \quad \text { and } \quad C>4
\end{gathered}
$$

In the proposed method, numerous populations are used as parallel to optimize the fitness function. In each step of a repeat, the each population will have been optimized the fitness function as separately, which motion vector for each population is modified as follows:

$$
v_{i+1}^{k+1}=K *\left(w_{i} v_{i}^{k}+c_{1} \text {.rand } .\left(\text { pbest }-x_{i}^{k}\right)+c_{2} \text {.rand }\left(\text { gbest }-x_{i}^{k}\right)+c_{3} \text {.rand } .\left(\text { gbest_total }-x_{i}^{k}\right)\right)
$$


In Eq. (7) coefficient $C_{3}$, is the weight coefficient of third relationship, which can be determined by trade of technique according to the type of optimization problem. gbest_total, is the best value of the gbest among all populations in each repetition. In this case, the particles of each population are up to date according to their population and other populations. This new solution increases the scope of the search and the speed of convergence. After repeating process which is considered, the each population will have an optimal solution. The ultimate answer, is the best choice from the different population. It is clear that the increasing of the data volume processing by increase the number of populations. The procedure to implement the proposed MPPSO technique is summarized in the diagram of Fig. 3 (a). The flowchart of the basic operation of the MPPSO shown in Fig. 3 (b) is explained as follows:

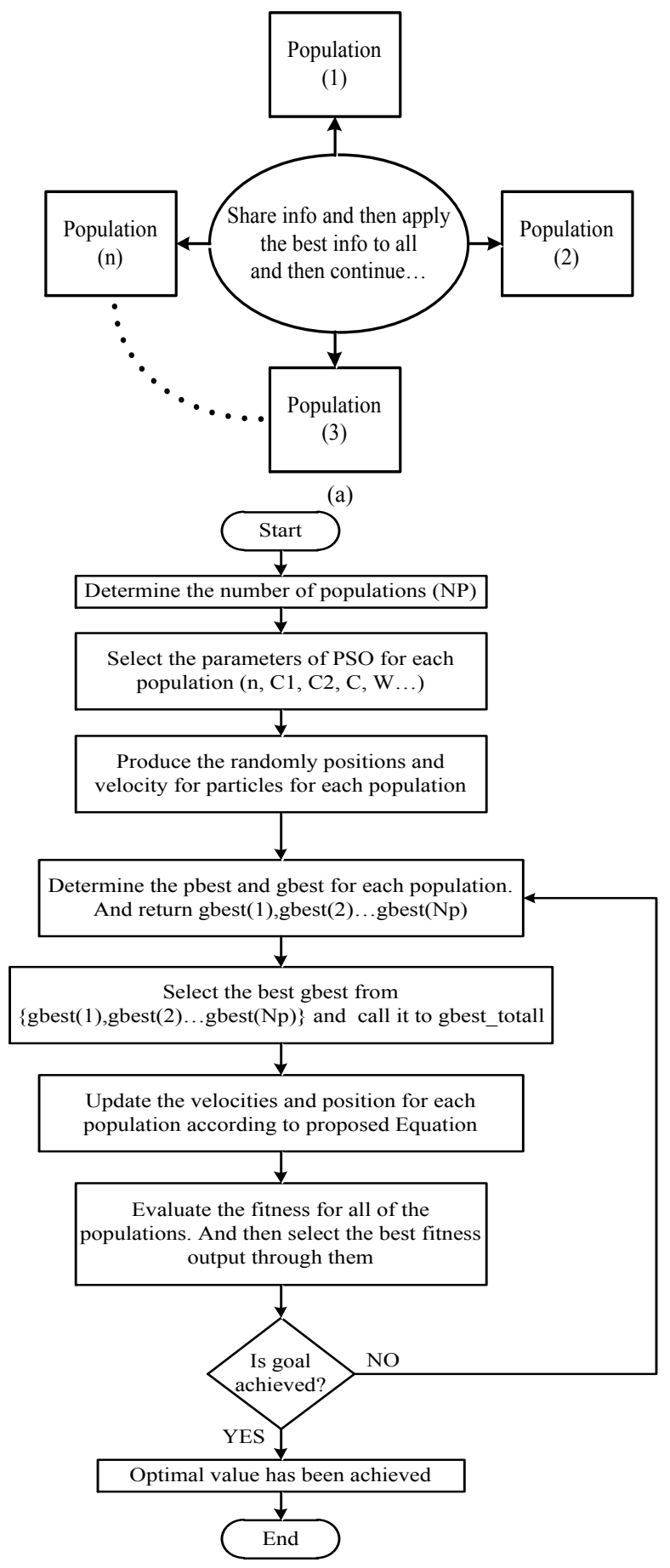

(b)

Fig. 3. (a) Block diagram of the implementation of the proposed MPPSO technique (b) Flowchart of MPPSO 
The idea here is the classic SHEPWM method that tries to find switching angles in order to eliminate first $N-1$ low order harmonics and control simultaneously the fundamental component. The triplen harmonics are not regarded as they are naturally cancelled out in the line to line voltages of a three phase system. In a mathematical form, the standard SHEPWM problem is formulated by the following set of equations.

$$
\begin{aligned}
& \sum_{i=1}^{S} \cos \left(\alpha_{i}\right)-S M=0 \\
& \sum_{i=1}^{S} \cos \left(5 \alpha_{i}\right)=0 \\
& \sum_{i=1}^{S} \cos \left(7 \alpha_{i}\right)=0 \\
& \vdots \\
& \sum_{i=1}^{S} \cos \left(n \alpha_{i}\right)=0
\end{aligned}
$$

Where $n=3 S-1$, when $S$ is even, and $n=3 S-2$, when $S$ is odd. $M$ is the modulation index and is determined in the following manner:

$$
M=\frac{\pi \cdot V_{1}}{4 S V_{d c}}(0<M \leq 1)
$$

To define the switching angles, the $S$ transcendental equations in Eq. (8) should be solved by MPPSO algorithm. According to the modulation index $M$, there are two areas: 1) feasible region in which there is a set or a numerous set of solutions for switching angles and the SHEPWM method can be successfully discovered, and 2) the infeasible area in which there is no solution for the equations in Eq. (8) And consequently, the low-order harmonics cannot be eliminated from the stepped voltage waveforms. As a result, the standard SHEPWM technique has a narrow modulation region and cannot be realized for the entire modulation range. In this paper, the MPPSO optimization algorithm tries to extend feasible range of modulation index compare with prior literature.

As an example, in a SHEPWM technique for a nine-level inverter, which generates a nine-level stepped voltage waveform, according to the equation sets of Eq. (8), four switching angles are computed to regulate the domain of the AC side voltage and to eliminate the harmonics of order 5, 7 and 11 with high accuracy by MPPSO optimization algorithm. As case study Eq. (8) Rewritten in the following manner:

$$
\begin{aligned}
& \cos \left(\alpha_{1}\right)+\cos \left(\alpha_{2}\right)+\cos \left(\alpha_{3}\right)+\cos \left(\alpha_{4}\right)=4 M \\
& \cos \left(5 \alpha_{1}\right)+\cos \left(5 \alpha_{2}\right)+\cos \left(5 \alpha_{3}\right)+\cos \left(5 \alpha_{4}\right)=0 \\
& \cos \left(7 \alpha_{1}\right)+\cos \left(7 \alpha_{2}\right)+\cos \left(7 \alpha_{3}\right)+\cos \left(7 \alpha_{4}\right)=0 \\
& \cos \left(11 \alpha_{1}\right)+\cos \left(11 \alpha_{2}\right)+\cos \left(11 \alpha_{3}\right)+\cos \left(11 \alpha_{4}\right)=0
\end{aligned}
$$

To solve the described set of equations for the SHEPWM technique, Eq. (10), and to determine the desired switching angles for any value of $M$, a minimization approach, based on a fitness function is used. Thus, via Eq. (11) as a novel fitness function, the whole of the mentioned goal done by MPPSO algorithm.

$$
\begin{aligned}
& \mathrm{f}_{1}=\cos \left(\alpha_{1}\right)+\cos \left(\alpha_{2}\right)+\cos \left(\alpha_{3}\right)+\cos \left(\alpha_{4}\right) \\
& \mathrm{f}_{2}=\cos \left(5 \alpha_{1}\right)+\cos \left(5 \alpha_{2}\right)+\cos \left(5 \alpha_{3}\right)+\cos \left(5 \alpha_{4}\right) \\
& \mathrm{f}_{3}=\cos \left(7 \alpha_{1}\right)+\cos \left(7 \alpha_{2}\right)+\cos \left(7 \alpha_{3}\right)+\cos \left(7 \alpha_{4}\right) \\
& \mathrm{f}_{4}=\cos \left(11 \alpha_{1}\right)+\cos \left(11 \alpha_{2}\right)+\cos \left(11 \alpha_{3}\right)+\cos \left(11 \alpha_{4}\right) \\
& \mathrm{y}_{1}=100 \times\left|\mathrm{f}_{1}-4 \mathrm{M}\right|+\left|\mathrm{f}_{2}\right|+\left|\mathrm{f}_{3}\right|+\left|\mathrm{f}_{4}\right| \\
& \mathrm{y}_{2}=\left|\mathrm{f}_{1}-4 \mathrm{M}\right|+100 \times\left|\mathrm{f}_{2}\right|+\left|\mathrm{f}_{3}\right|+\left|\mathrm{f}_{4}\right| \\
& \mathrm{y}_{3}=\left|\mathrm{f}_{1}-4 \mathrm{M}\right|+\left|\mathrm{f}_{2}\right|+100 \times\left|\mathrm{f}_{3}\right|+\left|\mathrm{f}_{4}\right| \\
& \mathrm{y}_{4}=\left|\mathrm{f}_{1}-4 \mathrm{M}\right|+\left|\mathrm{f}_{2}\right|+\left|\mathrm{f}_{3}\right|+100 \times\left|\mathrm{f}_{4}\right|
\end{aligned}
$$

$$
\text { Fitness Function }=\max \left(\left[\begin{array}{llll}
\mathrm{y}_{1} & \mathrm{y}_{2} & \mathrm{y}_{3} & \mathrm{y}_{4}
\end{array}\right]\right) \Rightarrow 0 \leq \alpha_{1} \leq \alpha_{2} \leq \alpha_{3} \leq \alpha_{4}<\frac{\pi}{2}
$$

In nonlinear equation which is shown in Eq. (10), one of the equations $f_{1}$ to $f_{4}$ has more value in the special point of the modulation index interval (zero to one), hence it will need to pay more attention to optimization. Therefore, in the relations y1 to y4, the integer constant of 100 is multiplied in one of the relations $f_{1}$ to $f_{4}$. Finally, in the fitness function which is shown in Eq. (11), the maximum amount of the $y_{1}$ to $y_{4}$ is determined for further consideration in the optimization algorithms. 


\section{Simulation Results}

In this section, presents the results of the implementation MPPSO algorithms to the SHEPWM nonlinear transcendental equations for the line voltage of 9 level inverter. The algorithm was run 20 times and the best answer is selected. Excellent answers criteria and in the other words, the ultimate goals, are included set the fundamental component to the desired value, eliminating low order harmonics with high accuracy, and extend the feasible range of modulation index.

In this example, four switching angles are seeking to eliminate the $5^{\text {th }}, 7^{\text {th }}$ and $11^{\text {th }}$ harmonics of the stepped voltage waveform, and adjust the fundamental component to the desired reference value. The switching angle solutions against $M$ are depicted in Fig. 4.

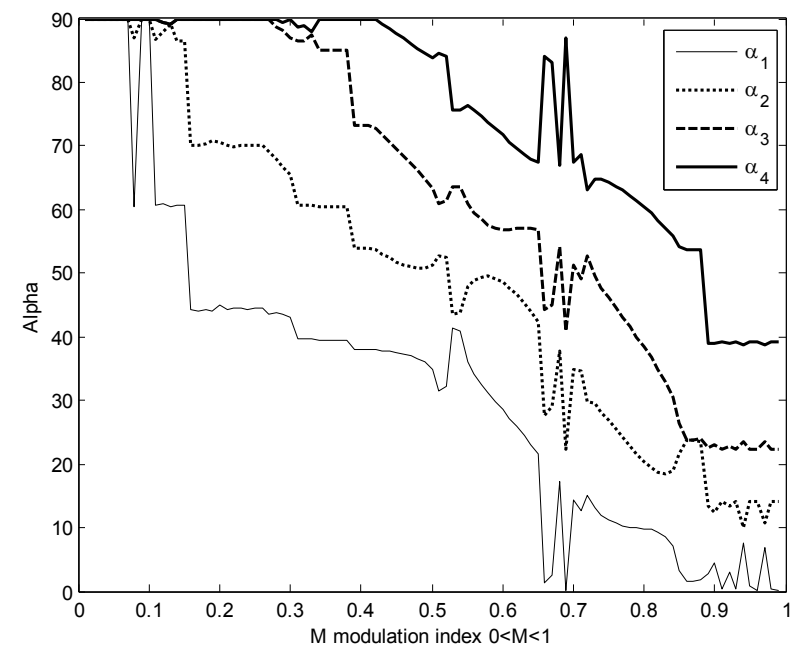

Fig. 4. Optimal switching angles via modulation index

The switching angles starting from 90 degree for small value of $M$, and close to zero for large value of $M$. Fitness function value against the modulation index is shown in Fig. 5.

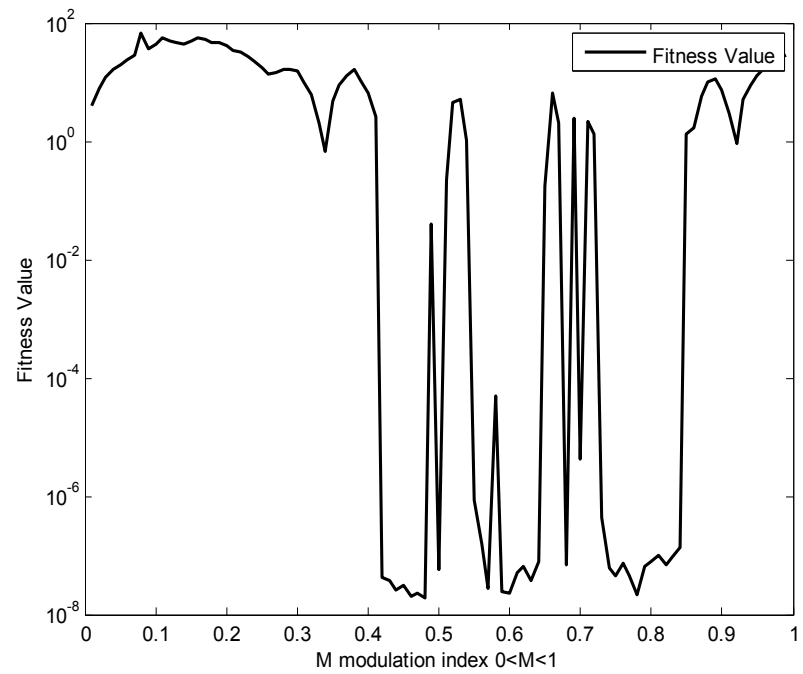

Fig. 5. Fitness function value via modulation index

Some corresponding values for the fitness function are larger than $10^{0}$ in the $0<M \leq 0.4$ and $0.87<M \leq 1$ interval of modulation index, because there is a grate integer constant in fitness function which is multiplied in $\mathrm{y}_{1}$ to $\mathrm{y}_{4}$. There are some excellent answer in the mentioned interval.

Compared with the prior literature [35], along with imposing more stringent conditions, the feasible interval of modulation index for the fundamental frequency component is $51 \%$ which given in Fig. 5, while the feasible interval of $M$ is achieved $31 \%$ in the prior literature [35]. As can be seen the MPPSO optimization algorithm has great potential in solving the nonlinear equations compare with general optimization algorithms such as GA or common PSO. The feasible regions in which the harmonics are eliminated with high accuracy and set the fundamental component to the desired value, are limited to $0.26 \leq \mathrm{M} \leq 0.30,0.33 \leq \mathrm{M} \leq 0.34$, $0.42 \leq \mathrm{M} \leq 0.51,0.54 \leq \mathrm{M} \leq 0.65,0.67 \leq \mathrm{M} \leq 0.87$ and $\mathrm{M}=0.93$. 
Fig. 6 shows the percentage of fifth, seventh and eleventh harmonic against modulation index.

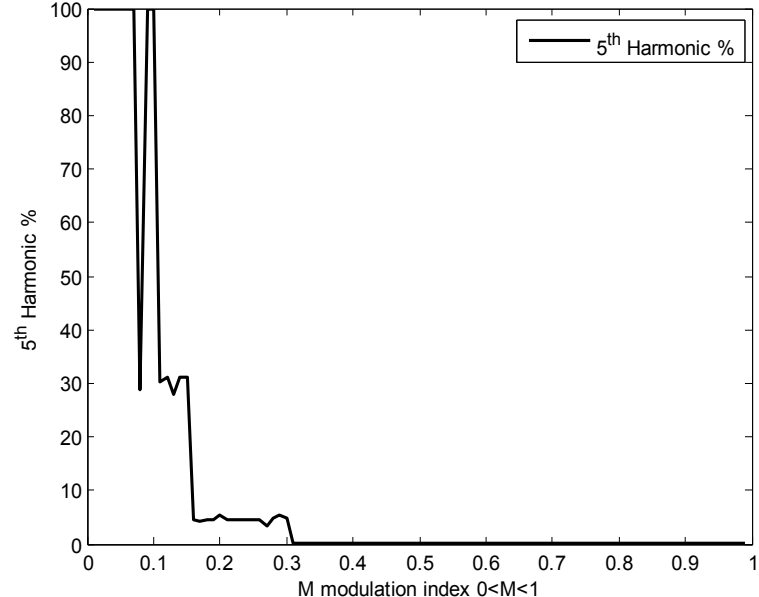

(a)

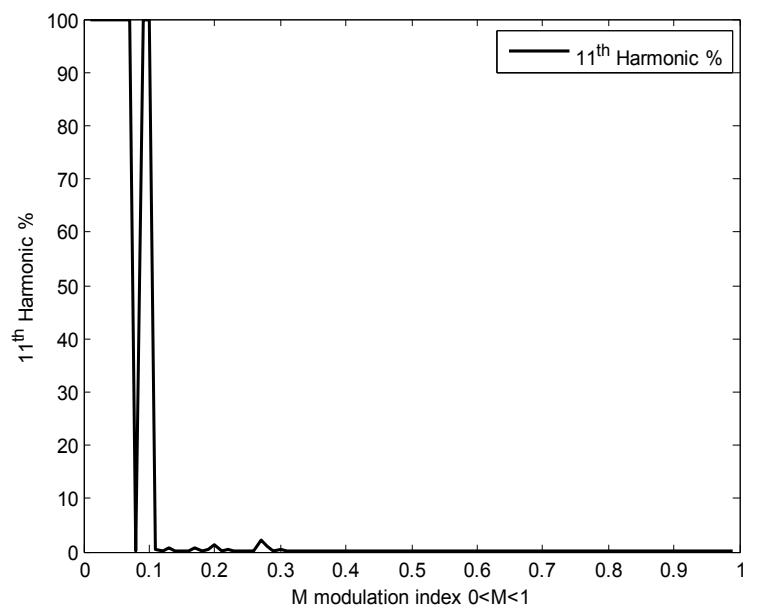

(c)

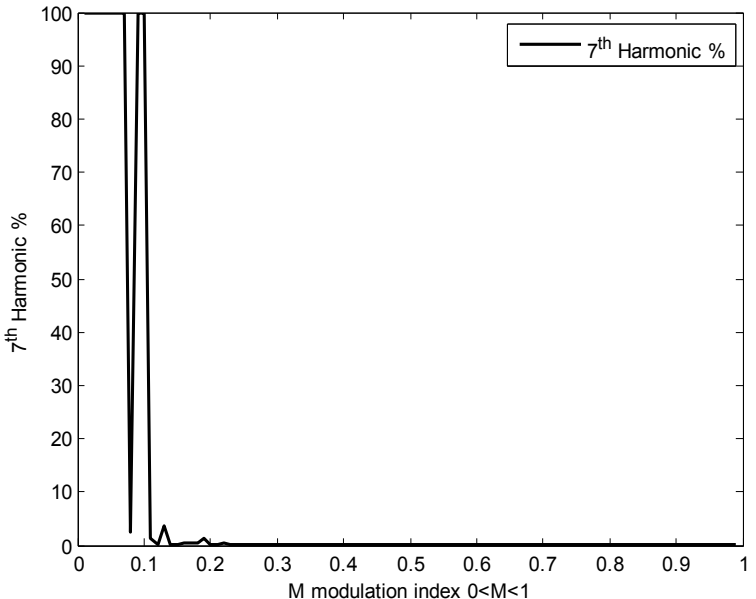

(b)

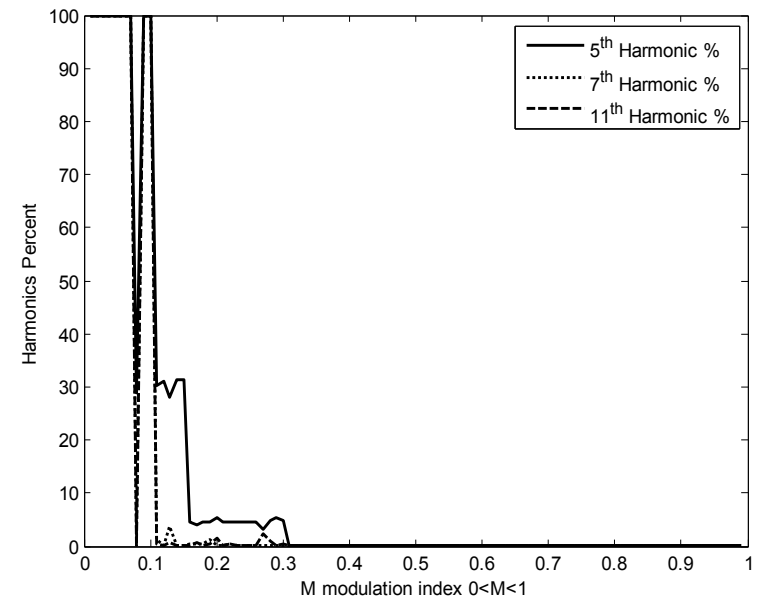

(d)

Fig. 6. a) Percentage of fifth harmonic against $M$, b) Percentage of seventh harmonic against $M$

c) Percentage of eleventh harmonic against $\mathrm{M}, \mathrm{d}$ ) Comparison between fifth, seventh and eleventh harmonic against $\mathrm{M}$

As Fig. 6 depicts the fifth, seventh and eleven harmonic are eliminated as completed in $0.31 \leq \mathrm{M} \leq 1$, $0.12 \leq \mathrm{M} \leq 1$ and $0.11 \leq \mathrm{M} \leq 1$ region, respectively.

\section{Conclusion}

This paper proposes a novel optimization algorithm MPPSO, to extend the feasible modulation range of the SHEPWM nonlinear transcendental equations of multilevel inverters. The problem of finding the switching angles of a SHEPWM is modified to eliminate low order harmonics with high accuracy and set the fundamental component to the desired value. The feasible rang of modulation index was reported in the prior literature is $31 \%$, by MPPSO algorithm this mentioned range extends to the $51 \%$. A novel optimization algorithm entitles MPPSO is used to solve the nonlinear transcendental equations of SHEPWM technique. The MPPSO optimization algorithm has great potential in solving the nonlinear equations compare with general optimization algorithms such as GA or common PSO. In this paper, the feasible range of modulation index is extended, moreover, in the infeasible rang of the modulation index, MPPSO algorithm minimizes low order harmonics and try to set the fundamental value to the desired value with one percentage of error, this is an accepted range of error. The capability of the proposed technique is investigated based on time-domain simulation studies, in the MATLAB environment. Effectiveness of the proposed MPPSO optimization algorithm is demonstrated under various operational scenarios. 


\section{Acknowledgements}

We are appreciative of Islamic Azad University of Abhar branch to afford us the opportunity to perform this research project.

\section{References}

[1]. J. Rodriguez, L. Jih-Sheng, and P. Fang Zheng, "Multilevel inverters: a survey of topologies, controls, and applications," Industrial Electronics, IEEE Transactions on, vol. 49, pp. 724-738, 2002.

[2]. N. Farokhnia, H. Vadizadeh, S. H. Fathi, and F. Anvariasl, "Calculating the Formula of Line-Voltage THD in Multilevel Inverter With Unequal DC Sources," Industrial Electronics, IEEE Transactions on, vol. 58, pp. 3359-3372, 2011.

[3]. G. Brando, M. Coppola, A. Dannier, A. Del Pizzo, and D. Iannuzzi, "An analysis of modular multilevel converter for full frequency range operations," in Ecological Vehicles and Renewable Energies (EVER), 2013 8th International Conference and Exhibition on, 2013, pp. 1-7.

[4]. Luci, x, O. a, Burdi, x, J. M. o, et al., "Efficiency-Oriented Design of ZVS Half-Bridge Series Resonant Inverter With Variable Frequency Duty Cycle Control," Power Electronics, IEEE Transactions on, vol. 25, pp. 1671-1674, 2010.

[5]. J. Dong, W. Fei, and X. Jing, "PWM Impact on CM Noise and AC CM Choke for Variable-Speed Motor Drives," Industry Applications, IEEE Transactions on, vol. 49, pp. 963-972, 2013.

[6]. A. Tessarolo, C. Bassi, G. Ferrari, D. Giulivo, R. Macuglia, and R. Menis, "Investigation Into the High-Frequency Limits and Performance of Load Commutated Inverters for High-Speed Synchronous Motor Drives," Industrial Electronics, IEEE Transactions on, vol. 60, pp. 2147-2157, 2013.

[7]. M. R. Banaei, M. R. Jannati Oskuee, and H. Khounjahan, "Reconfiguration of semi-cascaded multilevel inverter to improve systems performance parameters," Power Electronics, IET, vol. 7, pp. 1106-1112, 2014.

[8]. M. F. Kangarlu and E. Babaei, "A Generalized Cascaded Multilevel Inverter Using Series Connection of Submultilevel Inverters," Power Electronics, IEEE Transactions on, vol. 28, pp. 625-636, 2013.

[9]. C. I. Odeh and D. B. N. Nnadi, "Single-phase 9-level hybridised cascaded multilevel inverter," Power Electronics, IET, vol. 6, pp. 468-477, 2013.

[10]. A. Ajami, H. Shokri, and A. Mokhberdoran, "Parallel switch-based chopper circuit for DC capacitor voltage balancing in diodeclamped multilevel inverter," Power Electronics, IET, vol. 7, pp. 503-514, 2014.

[11]. J. Mathew, P. P. Rajeevan, K. Mathew, N. A. Azeez, and K. Gopakumar, "A Multilevel Inverter Scheme With Dodecagonal Voltage Space Vectors Based on Flying Capacitor Topology for Induction Motor Drives," Power Electronics, IEEE Transactions on, vol. 28, pp. 516-525, 2013.

[12]. E. Babaei, S. Alilu, and S. Laali, "A New General Topology for Cascaded Multilevel Inverters With Reduced Number of Components Based on Developed H-Bridge," Industrial Electronics, IEEE Transactions on, vol. 61, pp. 3932-3939, 2014.

[13]. D. Dujic, M. Jones, E. Levi, J. Prieto, and F. Barrero, "Switching Ripple Characteristics of Space Vector PWM Schemes for FivePhase Two-Level Voltage Source Inverters-Part 1: Flux Harmonic Distortion Factors," Industrial Electronics, IEEE Transactions on, vol. 58, pp. 2789-2798, 2011.

[14]. W. Fei, X. Du, and B. Wu, "A generalized half-wave symmetry SHE-PWM formulation for multilevel voltage inverters," IEEE Transactions on Industrial Electronics, vol. 57, pp. 3030-3038, 2010.

[15]. N. Farokhnia, S. H. Fathi, N. Yousefpoor, and M. K. Bakhshizadeh, "Minimisation of total harmonic distortion in a cascaded multilevel inverter by regulating voltages of dc sources," Power Electronics, IET, vol. 5, pp. 106-114, 2012.

[16]. H. Belkamel, S. Mekhilef, A. Masaoud, and M. A. Naeim, "Novel three-phase asymmetrical cascaded multilevel voltage source inverter," Power Electronics, IET, vol. 6, pp. 1696-1706, 2013.

[17]. I. Ahmed and V. B. Borghate, "Simplified space vector modulation technique for seven-level cascaded H-bridge inverter," Power Electronics, IET, vol. 7, pp. 604-613, 2014.

[18]. N. Sujitha and K. Ramani, "A new Hybrid Cascaded H-Bridge Multilevel inverter - Performance analysis," in Advances in Engineering, Science and Management (ICAESM), 2012 International Conference on, 2012, pp. 46-50.

[19]. Y. Suresh and A. K. Panda, "Research on a cascaded multilevel inverter by employing three-phase transformers," Power Electronics, IET, vol. 5, pp. 561-570, 2012.

[20]. T. Kato, "Sequential homotopy-based computation of multiple solutions for selected harmonic elimination in PWM inverters," Circuits and Systems I: Fundamental Theory and Applications, IEEE Transactions on, vol. 46, pp. 586-593, 1999.

[21]. D. Zhong, L. M. Tolbert, J. N. Chiasson, and B. Ozpineci, "Reduced Switching-Frequency Active Harmonic Elimination for Multilevel Converters," Industrial Electronics, IEEE Transactions on, vol. 55, pp. 1761-1770, 2008.

[22]. K. Sundareswaran, K. Jayant, and T. N. Shanavas, "Inverter Harmonic Elimination Through a Colony of Continuously Exploring Ants," Industrial Electronics, IEEE Transactions on, vol. 54, pp. 2558-2565, 2007.

[23]. J. Vicente, R. Pindado, and I. Martinez, "Design guidelines using selective harmonic elimination advanced method for DC-AC PWM with the Walsh transform," in Compatibility and Power Electronics (CPE), 20117 th International Conference-Workshop, 2011, pp. 220-225.

[24]. B. Ozpineci, L. M. Tolbert, and J. N. Chiasson, "Harmonic optimization of multilevel converters using genetic algorithms," Power Electronics Letters, IEEE, vol. 3, pp. 92-95, 2005.

[25]. M. Sarvi and M. R. Salimian, "Optimization of specific harmonics in multilevel converters by GA \&amp; PSO," in Universities Power Engineering Conference (UPEC), 2010 45th International, 2010, pp. 1-4.

[26]. K. Chaniago, N. A. Rahim, and J. Selvaraj, "Novel fundamental-frequency-modulated modified H-bridge single-phase seven-level inverter for stand-alone photovoltaic system," in Clean Energy and Technology (CET), 2011 IEEE First Conference on, 2011, pp. 225-230.

[27]. H. S. Patel and R. G. Hoft, "Generalized Techniques of Harmonic Elimination and Voltage Control in Thyristor Inverters: Part I-Harmonic Elimination," Industry Applications, IEEE Transactions on, vol. IA-9, pp. 310-317, 1973.

[28]. J. Kennedy, "The particle swarm: social adaptation of knowledge," in Evolutionary Computation, 1997., IEEE International Conference on, 1997, pp. 303-308.

[29]. T. Jeevabharathi and V. Padmathilagam, "Harmonic elimination of Cascaded Multilevel Inverters Using Particle Swarm Optimization," in Computing, Electronics and Electrical Technologies (ICCEET), 2012 International Conference on, 2012, pp. 301 306.

[30]. D. Holmes and T. Lipo, Pulse Width Modulation For Power Converters Principles and Practice: Wiley-IEEE Press, 2003.

[31]. P. M. Bhagwat and V. R. Stefanovic, "Generalized Structure of a Multilevel PWM Inverter," Industry Applications, IEEE Transactions on, vol. IA-19, pp. 1057-1069, 1983. 
[32]. M. S. A. Dahidah and V. G. Agelidis, "Selective Harmonic Elimination PWM Control for Cascaded Multilevel Voltage Source Converters: A Generalized Formula," Power Electronics, IEEE Transactions on, vol. 23, pp. 1620-1630, 2008.

[33]. B. Zhao, C. X. Guo, and Y. J. Cao, "A multiagent-based particle swarm optimization approach for optimal reactive power dispatch," Power Systems, IEEE Transactions on, vol. 20, pp. 1070-1078, 2005.

[34]. K. Qi, Z. Mengchu, A. Jing, and W. Qidi, "Swarm Intelligence Approaches to Optimal Power Flow Problem With Distributed Generator Failures in Power Networks," Automation Science and Engineering, IEEE Transactions on, vol. 10, pp. 343-353, 2013.

[35]. N. Farokhnia, S. H. Fathi, R. Salehi, G. B. Gharehpetian, and M. Ehsani, "Improved selective harmonic elimination pulse-width modulation strategy in multilevel inverters," Power Electronics, IET, vol. 5, pp. 1904-1911, 2012. 